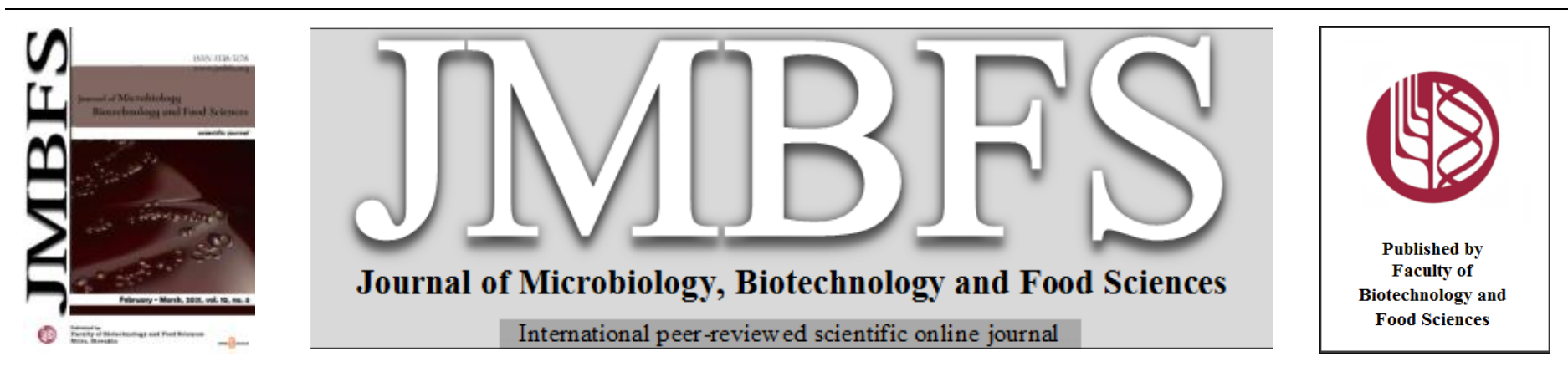

\title{
RIPENING DELAY OF 'SABA' BANANA USING CHITOSAN COATING MATERIAL FROM THE TEST WASTES OF PHILIPPINE BLUE-EYED SEA URCHIN
}

\author{
Betti Mae C. Mendoza, Neil Ian V. Magalang, Aurora Blanca M. Lalo, Romnick M. Ureta*
}

Address(es):

MIMAROPA Regional Science High School-Senior High School Department, Pag-asa, 5210, Bansud, Oriental Mindoro, Philippines.

*Corresponding author: romnickm.ureta@gmail.com

doi: 10.15414/jmbfs.2021.10.4.566-571

\section{ARTICLE INFO}

Received 30. 3. 2020

Revised 25. 9. 2020

Accepted 2. 10. 2020

Published 1. 2. 2021

Regular article

open $\partial_{\text {access }}$

\begin{abstract}
Postharvest loss of bananas due to ripening acceleration is one of the problems of local Filipino farmers. This problem has resulted in profit losses which could bring serious effects in the agricultural sector. Thus, this study aims to derive chitosan, a biopolymer and nontoxic material from the test wastes of the Philippine blue-eyed sea urchins (Diadema savignyi Michelin, 1845) to be used as a surface coating for 'Saba' banana (Musa $x$ paradisiaca) to delay the ripening process. The chitosan was obtained by decolorization, pulverization, deproteinization, demineralization, and deacetylation of the sea urchins' tests. The derived chitosan was validated by its Degree of Acetylation (DA) (35.65\%) based on amino and hydroxyl group at peaks $1645.25 \mathrm{~cm}^{-1}$ and $3469.63 \mathrm{~cm}^{-1}$. Scanning Electron Microscopy (SEM) micrographs confirmed the amorphous and non-homogeneous structure of chitosan. Results also showed that the chitosan-coated bananas had lower weight loss, greener color, firmer, and lower disease incidence after the seven-day observation as compared with that of the uncoated samples. The study implies that the synthesized chitosan from the test wastes of Philippine blueeyed sea urchin can be a potential natural coating material in delaying the rapid ripening of 'Saba' banana.
\end{abstract}

Keywords: Biopolymer, Fruit surface coating, Postharvest loss of Banana, Diadema savignyi

\section{INTRODUCTION}

Banana is one of the most useful and available fruits in the world, both in commercial and local trade. It is considered as an important crop that is widely cultivated in tropical countries for its many applications in the food industry. This fruit serves as the main source of income for local farmers in an agricultural country like the Philippines.

In the province of Oriental Mindoro, there has been always the greatest demand for fresh banana fruits. But recently, the majority of the local farmers and fruit distributors are experiencing post-harvest problems due to rapid ripening and fault storage processes. The problem in proper storage of the fruit may lead to some mechanical injuries which could possibly generate dark brown to black markings in the fruit. Bruised bananas are not visually attractive making them undesirable for customers (Bugaud et al., 2014). On the other hand, bananas are normally harvested before fully mature for domestic consumption. Usually, bananas are stored at room temperature. During storage, banana fruit is easily deteriorated due to the quick ripening process. The ripening process is considered a very complex event, characterized by intense changes in physiological and biochemical parameters such as chlorophyll degradation, enzymatic cell wall degradation, changes in sugar content, respiratory activity, ethylene production, and in the levels of aromatic compounds (Giovannoni, et al., 2017). This postharvest problem of rapid ripening directly affects the income and profit of fruit distributors and local banana producers.

Meanwhile, the southernmost part of Oriental Mindoro, particularly the town of 'Bulalacao' is becoming popular because of its beautiful beaches and shorelines. Species of sea urchin, Philippine Diadema savignyi Michelin, 1845, or commonly called the blue-eyed sea urchin or the black long-spined sea urchin has invaded the shallow parts of the seas near the coastlines. The locals are collecting this urchin species to eat its flesh which is known to be nutritious. After consuming it, locals are dumping the tests (shells) on the shores.

According to Kanold $\boldsymbol{e t}$ al. (2015), sea urchins possess calcified hard parts such as tests, spines, and teeth that display a variety of shapes and fulfill different biological functions. Calcified structures of sea urchins are biocomposite materials that comprise a minor fraction of organic macromolecules, such as proteins, glycoproteins, and polysaccharides. Marine shell wastes like the tests of urchin species is a very rich source of several bioactive compounds and materials such as calcium, chitin pigments, and proteins. These wastes from the shells of seafood contain 20-30\% of chitin (Hou et al., 2016).
Recently, several studies have developed ways on how to address problems on the post-harvest of the fruits. However, utilizing synthetic chemical materials in fruit preservation gives concern to consumers' safety. Thus, the formulations of fruit coatings or edible films have been studied. The edible film is a thin layer of material which can be eaten by the consumer, may be applied on or within the food by wrapping, dipping, brushing or spraying and acts as barriers against transmission of gases, vapors, and solutes and provide mechanical protection (Wu et al., 2002).

Chitosan has been widely used as an edible coating for extending the shelf life of fruits (Suseno et al., 2014). It is a polysaccharide derived from the $\mathrm{N}$ deacetylation of chitin which exhibits numerous interesting physicochemical and biological properties. Chitosan is a natural and non-toxic material that can be extracted from shells of organisms like in those crustaceans. This polysaccharide has found numerous applications in various fields such as waste-water treatment, agriculture, cosmetics, and food processing. Due to its biocompatibility, biodegradability, and bioactivity, it is more and more considered as a very interesting substance for diverse applications as a biomaterial (Chatelet $\boldsymbol{e t}$ al., 2001).

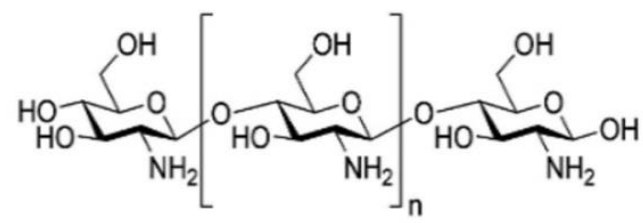

Figure 1 Chemical structure of chitosan (Mahapatro and Singh, 2011)

In this study, the researchers have come up with a potential solution to the postharvest problem in banana due to ripening acceleration by deriving chitosan from the tests or shells of the Philippine blue-eyed sea urchin (Diadema savignyi Michelin, 1845). The chitosan to be produced will be used as a surface coating to 'Saba' banana (Musa x paradisiaca) and be observed if it can delay the ripening process of the fruit. Meanwhile, the blue-eyed sea urchin species is not listed on the IUCN Red List of Threatened Species, suggesting that it is currently not under threat (Muthiga \& McClanahan, 2007) which made it as a good potential source of the biopolymer material. This work also used a bamboo-based fruit 
storage chamber. According to Pratiwi et al. (2015), bamboo material does not cause any autocatalytic reaction to the ethylene gas produced by the banana during the ripening process.

Thus, this study primarily aims to synthesize and characterize chitosan material from the test wastes of Philippine blue-eyed urchin. Also, this work also assesses the potential of the produced chitosan in delaying the ripening of banana fruit

\section{MATERIALS AND METHODS}

\section{Collection and Preparation of Blue-eyed Sea Urchin}

One hundred twenty pieces of Blue-eyed sea urchin tests were collected at Pocanil and Buyayao, Bulalacao, Oriental Mindoro while the samples of unripe medium-sized ' $S a b a$ ' banana with a length of $10-12 \mathrm{~cm}$, a diameter of $4-5 \mathrm{~cm}$, and weight of 81.1-119.2g were provided by the Municipal Agriculture Center Moreover, the bamboo that was used in the fruit storage chamber were obtained at Gloria, Oriental Mindoro. All these materials were validated and certified for their binomial nomenclature at the National Institute of Biology at the University of the Philippines-Diliman.

The Blue-eyed sea urchin tests were washed with running tap water to remove soluble organics and visible impurities. The tests were treated in $6 \%$ sodium hypochlorite for 24 hours for the decolorization process and were sundried for 24 hours. Size reduction was done through mortar and pestle and mechanical blender. The powdered Blue-eyed sea urchin tests were stored in a glass bottle at ambient temperature for further analysis.

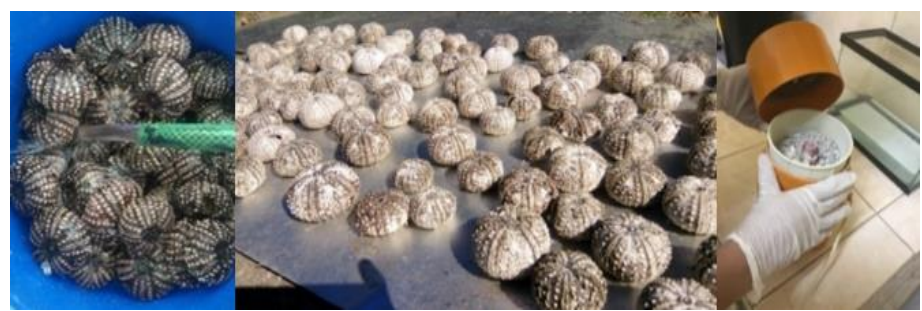

Figure 2 Preparation (cleaning, bleaching, and powdering) of the Blue-eyed sea urchin tests.

\section{Production and Characterization of Chitosan Blue-eyed Sea Urchin Test Wastes}

The production of the chitosan powder was executed following the standardized procedures of Majekodunmi et al. (2017) with some modifications.

Prior to the process, the blue-eyed sea urchin tests were soaked to $5 \%$ acetic acid to initially lessen some major minerals in the material like calcium carbonate. The pre-treated urchin tests underwent deproteinization using $4 \%$ sodium hydroxide $(1: 2 \mathrm{w} / \mathrm{v})$ and were subjected to continuous stirring using magnetic stirrer until bubbles and foam disappeared. It was then stored at room temperature for 24 hours. The residue was washed with distilled water repeatedly to remove other mineral contents with $\mathrm{pH}$ set to neutral.

The deproteinized powder was demineralized by treating it with $4 \%$ hydrochloric acid with a ratio of solute to solvent of $1: 10(w / v)$. The mixture was stirred using magnetic stirrer until bubbles disappeared followed by a 12-hour treatment at room temperature. The acid was drained and the residue was washed repeatedly with distilled water. Neutral $\mathrm{pH}$ was monitored. The process was repeated using $2 \%$ sodium hydroxide $(1: 2 w / v)$ and then with $1 \%$ hydrochloric acid, 1:10 (w/v) ratio. Crude chitin was produced after the process.

The $34 \mathrm{~g}$ chitin from the blue-eyed sea urchin tests was deacetylated using $65 \%$ $(w / v)$ sodium hydroxide $(\mathrm{NaOH})$ with a solute to the solvent ratio of 1:2 $(w / v)$ and was treated for three days. The deacetylated chitin was washed repeatedly with distilled water to remove some suspended particles. It was then filtered and airdried. The derived chitosan was then stored in a separate glass bottle for its further characterization and application.

\section{Functional Group Identification and Morphology Evaluation of the Chitosan}

Identification of the functional groups present was analyzed through a Fourier Transform Infrared Spectroscopy (FT-IR) at De La Salle University.

Approximately ten milligrams $(10 \mathrm{mg}$ ) of the chitosan powder and $60 \mathrm{mg}$ of $\mathrm{KBr}$ were blended and triturated with mortar and pestle for ten minutes. The mixture was compacted to form a disk (thin pellet) before putting it inside the Thermo Scientific Nicolet 6700 for analysis (Hussain et al., 2013). Moreover, the surface morphology of the chitosan derived from the blue-eyed sea urchin test was evaluated using JSM-5310 Scanning Electron Microscope. A small amount of the chitosan powder was placed in a small metal platform holder using carbon tape and underwent auto fine coating using JEOL JFC-1200 Fine Coater. Three frames of micrographs were generated for the chitosan powder given at different magnifications.

\section{Physicochemical Properties of the Chitosan Powder}

The degree of acetylation (DA) of chitosan, defined as the proportion of acetylglucosamine units in the polymer, and dependent on the deacetylation done. The DA was determined by Fourier Transform Infrared Spectroscopy (FT-IR) and was calculated from the obtained spectra using the equation proposed by Domszy and Roberts as cited by de Queiroz Antonino et al. (2017) and Brugnerotto et al. (2001). Moreover, the $\mathrm{pH}$ measurement of the chitosan solution was carried out using probed $\mathrm{pH}$ meter while $2 \mathrm{~g}$ of the chitosan powder was dissolved in $20 \mathrm{ml} 1 \%$ acetic acid solution in a beaker for $30 \mathrm{~min}$ on a magnetic stirrer at $250 \mathrm{rpm}$ at $25^{\circ} \mathrm{C}$ for the solubility test. After 30 minutes of agitation, the solution was filtered. The retardant (insoluble fraction) collected on the membrane filter was washed with distilled water then dried. Chitosan solubility in percentage was calculated by the following equation: Solubility (\%) $=100-[($ Weight of insoluble fraction/Initial weight of sample)*100] (Agarwal $\boldsymbol{e t}$ al., 2018).

\section{Coating of the Banana Samples}

In coating the banana samples, $0.5 \%(\mathrm{w} / \mathrm{v})$ chitosan solution was prepared by dissolving 5 grams of chitosan into the solution of $0.5 \%(\mathrm{v} / \mathrm{v})$ acetic acid with 25\% glycerol as plasticizer (w/w chitosan) (Park et al., 2004) under vigorous stirring and was filtered to remove insoluble materials. The mixture was stirred continuously until homogenous obtaining a $\mathrm{pH}$ of 6-7 by the gradual addition of $30 \mathrm{ml} 1 \mathrm{~N} \mathrm{NaOH}$ (Abd-Alla and Haggag, 2010). The banana samples were dipped in the chitosan solution for three minutes and were dried at room temperature for about 30 minutes. The coated fruits were then put into a Fruit Storage Chamber (FSC) (Pratiwi et al., 2015) made from 'Tinikan' bamboo measuring 22 inches long, 12 inches wide, and 6 inches tall. Ten FSCs with ten equal compartments were prepared.Effect of the Derived Chitosan on the

\section{Banana Shelf Life}

The evaluation of the banana samples after the application of the derived chitosan was conducted in the Municipal Agriculture Center with the direct supervision of an agriculturist knowledgeable in banana production. A total of 100 bananas were used in the experiment (50 chitosan-coated and 50 as control fruits). Day 0 was the day when bananas were coated with chitosan solution. The first day of observation started 24 hours after the coating process. The bananas were observed for seven days.

The weight loss percentage was measured every day and was calculated based on the comparison of the weight of the banana sample from their initial condition to their final condition. The percentage of weight loss was calculated by dividing the difference between the initial and final weights of the banana sample by the initial weight multiplied to $100 \%$. Meanwhile, hand feeling was applied in the evaluation of the firmness of the fruit within the seven days of storage based on the scaling presented by Garcia (2011) wherein the ratings are given as 1 - firm, 2 -yielding, 3-moderately soft, and 4=soft. Meanwhile, days required to reach different stages of color during storage and ripening were determined objectively using a numerical rating scale based on the Von Loesecke ripening scale (Gomes et al., 2013). Moreover, the disease incidence was identified symptomatically based on the standards of the Philippine National Standard for Fresh Fruit 'Saba' and 'Cardaba' bananas (DTI-Philippines, 2004) by dividing the number of infected bananas by the total number of banana samples multiplied to 100 (Sivakumar et al., 2002).

The experimentation results were expressed as mean. One-Way Analysis of Variance was employed via QI Macros SPC software in analyzing and determining the Least Significant Difference (LSD) at 0.05 level in the given sets of data.

\section{RESULTS}

\section{Morphology Evaluation using SEM}

One of the ways in characterizing the synthesized biopolymeric materials is through its morphology and surface structure. Several works about chitosan production claimed that this natural polymer possesses common physical and surface descriptions. It is common for chitosan to have unclear shape or form. In this study, SEM images at 1,000x, 5,000x and 15,000x magnifications showed that the chitosan derived from the test wastes of Philippine blue-eyed sea urchin had an amorphous and non-homogenous structure (Figure 3). 


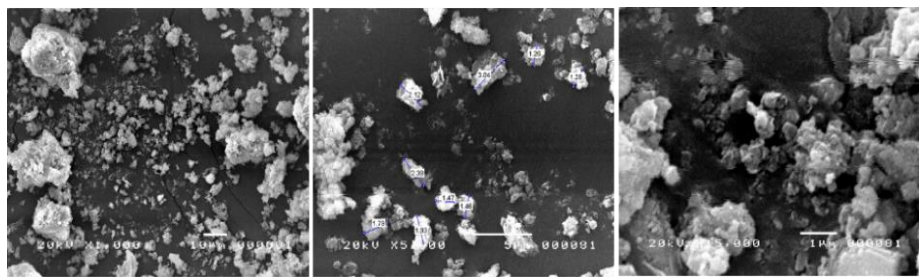

Figure 3 SEM of chitosan synthesized from the test wastes of Blue-eyed sea urchin.

\section{FT-IR Analysis}

Identification of the functional group assignments is one of the processes in characterizing certain material. These functional groups are specific groupings of atoms within molecules that have their characteristic properties, regardless of the other atoms present in a molecule. Fourier Transform Infrared Spectroscopy (FTIR) was used to identify the functional group of the synthesized chitosan.

The FT-IR profile of the chitosan extracted from the tests of Blue-eyed sea urchin showed absorption peaks of $1645.25 \mathrm{~cm}^{-1}$ for amino group, $3469.63 \mathrm{~cm}^{-1}$ for hydroxyl group, $2000 \mathrm{~cm}^{-1}$ to $1650 \mathrm{~cm}^{-1}$ for C-H band, and $1815 \mathrm{~cm}^{-1}$ to $1785 \mathrm{~cm}$ ${ }^{1}$ for $\mathrm{C}=\mathrm{O}$ band. Other absorption bands such as $\mathrm{O}-\mathrm{H}$ (alcohols) and carboxylic acid were located within the ranges of $3700 \mathrm{~cm}^{-1}$ to $3584 \mathrm{~cm}^{-1}, 3550 \mathrm{~cm}^{-1}$ to 3200 $\mathrm{cm}^{-1}$, and $3300 \mathrm{~cm}^{-1}$ to $2500 \mathrm{~cm}^{-1}$.

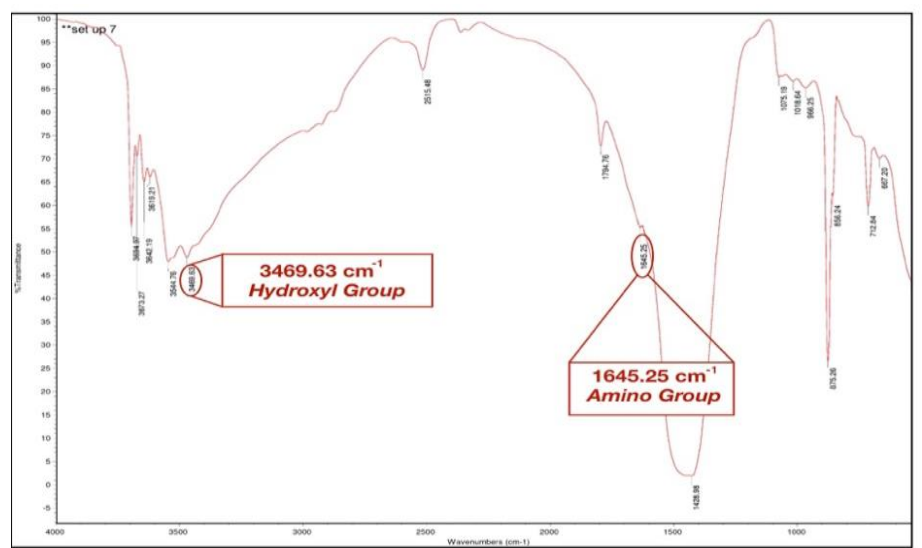

Figure 4 FT-IR spectrum of the synthesized chitosan from the test wastes of blue-eyed sea urchins.

\section{Physicochemical Properties of the Chitosan}

To further characterize certain biopolymers like chitosan, DA, solubility, $\mathrm{pH}$, and the yield percentage are necessary parameters. Chitosan has defined DA $<50 \%$ to signify that the chitin was deacetylated successfully. Moreover, the solubility of chitosan is mainly associated with its DA so as the $\mathrm{pH}$ level. Meanwhile, the yield is an important parameter to be considered to measure how the material can be maximized properly during actual production. Table 1 shows that chitosan derived from Philippine blue-eyed sea urchin yielded $44.11 \%$ using chitin as a reference and $7.5 \%$ when based on the initial weight of the powder. Moreover, the DA of the chitosan was $35.65 \%$, with $70 \%$ solubility and $\mathrm{pH}$ of 6.5 .

Table 1 Description of the chitosan powder obtained from the test wastes of blue-eyed sea urchin.

\begin{tabular}{|c|c|c|c|c|c|}
\hline & $\begin{array}{l}\text { \% Yield (Using obtained } \\
\text { chitin as reference) }\end{array}$ & $\begin{array}{c}\% \text { Yield (Based on initial } \\
\text { weight of the powder) }\end{array}$ & $\begin{array}{c}\text { Degree of } \\
\text { Acetylation (DA) }\end{array}$ & $\%$ Solubility & $\mathrm{pH}$ \\
\hline $\begin{array}{l}\text { Derived chitosan from } \\
\text { Philippine blue-eyed } \\
\text { sea urchin }\end{array}$ & $44.11 \%$ & $7.5 \%$ & $35.65 \%$ & $70 \%$ & 6.5 \\
\hline
\end{tabular}

\section{Effects of the Synthesized Chitosan on the Weight Loss of Banana}

Weight loss is a useful parameter that could directly be associated with fruit ripening. Several studies found that as the ripening process goes on, weight loss becomes more evident. This was also evident in Figure 5 wherein, bananas without treatment exhibited higher weight loss percentage with a mean of 5.41compared with that of chitosan coated bananas which had a lower weight loss percentage of 3.96 after the seven-day treatment.

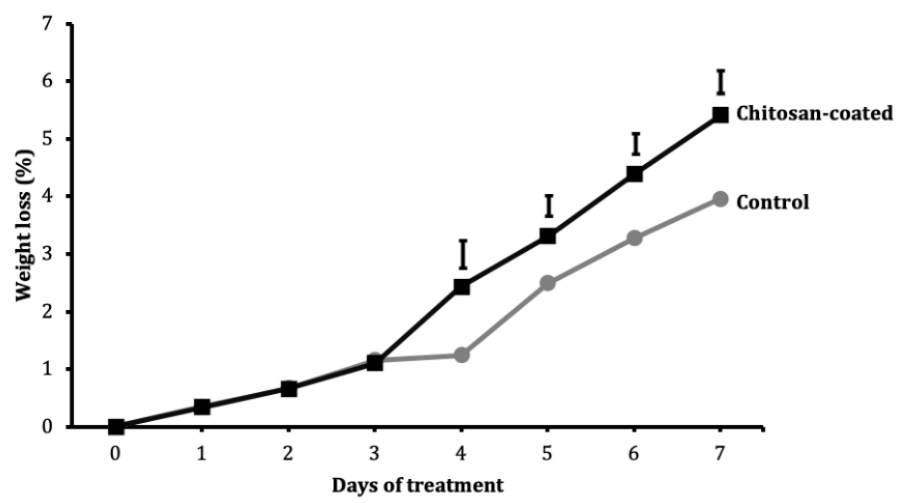

Figure 5 Average weight loss percentage of the uncoated (control) and chitosancoated bananas after the seven-day treatment. Bars show the Least Significant Difference (LSD) at 0.05 level.

\section{Peel Color Evaluation of Banana Coated with the Synthesized Chitosan}

Change in the peel colors is a common indicator of the fruit ripening process. In Figure 6, it was found that the color of chitosan-coated bananas had an average rating of 4 which corresponded to green color but with yellow portions while the control fruit had an average rating of 7 which denoted a yellow color with existing brown spots.

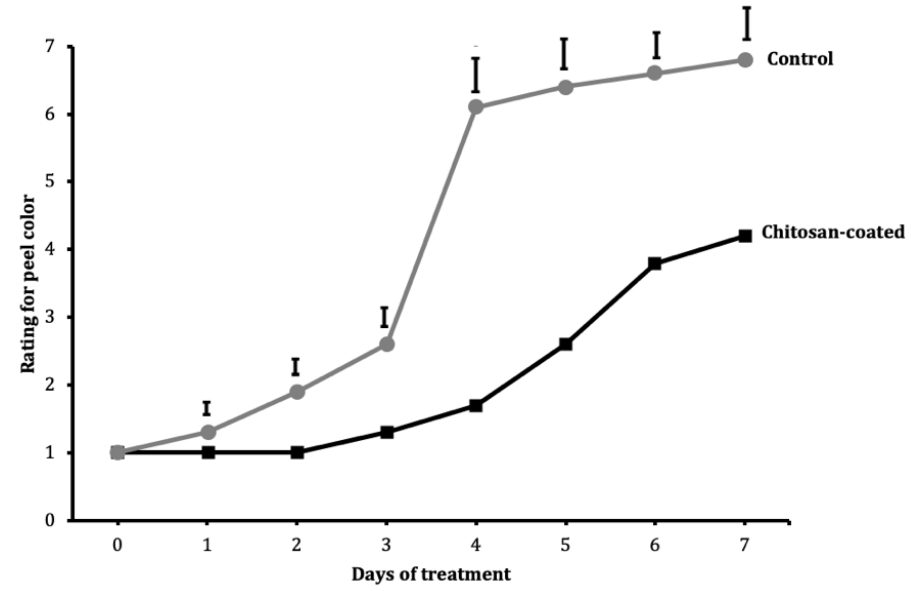

Figure 6 Average ratings for the peel colors of the uncoated (control) and chitosan-coated bananas after the seven-day treatment. Bars show the Least Significant Difference (LSD) at 0.05 level.

\section{Effects of the Synthesized Chitosan on the Firmness of Banana}

The firmness of the fruit is an indicator of its ripeness. Several works explained that the softer the fruit, the riper the fruit is. In Figure 7, chitosan-coated bananas remained firm from day 0 to 4 and reached moderate softness on day 7 . Moreover, the uncoated bananas started losing firmness since day 1 and had exhibited total softness starting day 4 . 


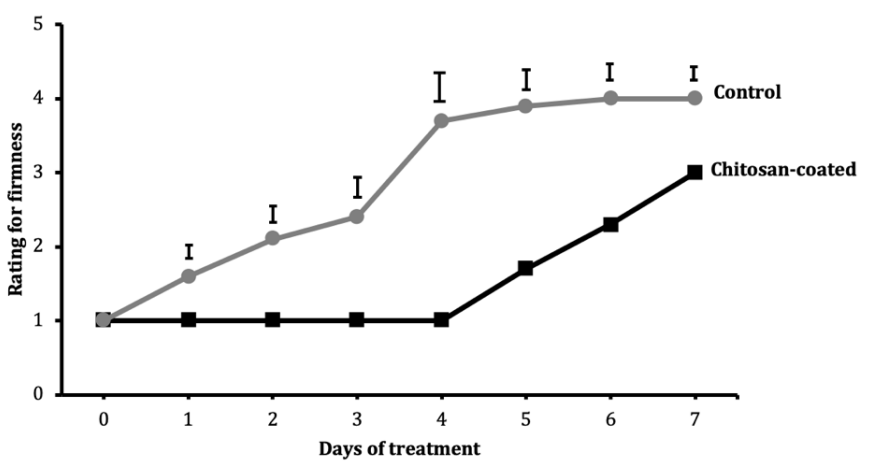

Figure 7 Average ratings for firmness of the uncoated (control) and chitosancoated bananas after the seven-day treatment. Bars show the Least Significant Difference (LSD) at 0.05 level.

Evaluation of the Disease Incidence Percentage of Bananas Coated with the Synthesized Chitosan

The occurrence of diseases in fruit becomes more evident during the ripening process. Commonly, ripe fruits have manifestation of several diseases. Figure 8 shows that the chitosan-coated bananas had lower disease incidence compared with that of the control after the seven-day treatment.

In chitosan-coated bananas, disease incidence was $40 \%$ in day 1 , slightly increased to $50 \%$ in day 4 and reached $90 \%$ in day 7 . Meanwhile, disease proliferation among the uncoated bananas was already high in day $1(60 \%$ incidence) and rapidly reached to $100 \%$ at day 5 .

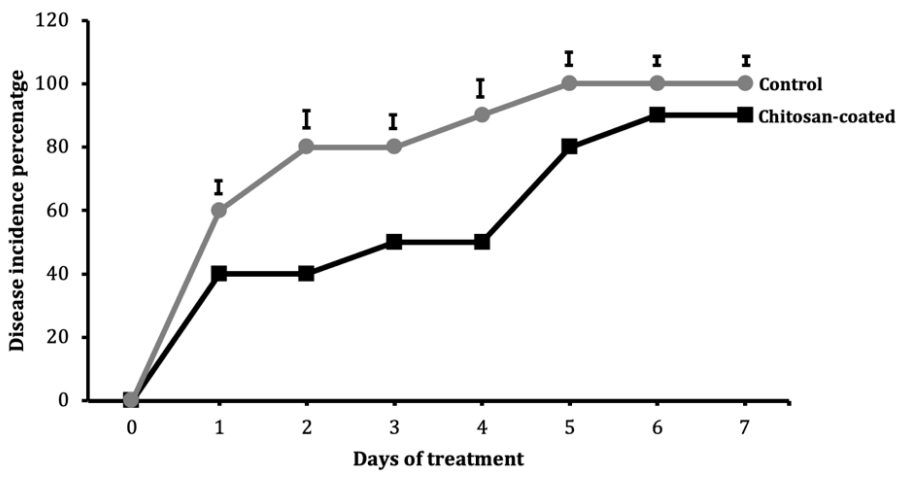

Figure 8 Average disease incidence percentage of the uncoated (control) and chitosan-coated bananas after the seven-day treatment. Bars show the Least Significant Difference (LSD) at 0.05 level.

\section{DISCUSSION}

The morphology of the chitosan derived from the test wastes of blue-eyed sea urchin showed non-homogenous and nonsmoothed surface and as the magnification increased, particle distribution became rougher. These observations were also evident in the study of Rafeeq $\boldsymbol{e t}$ al. (2010), El-Hefian $\boldsymbol{e t}$ al. (2010), and Majekodunmi et al. (2017). The nonsmoothed and rougher surface of certain material could indicate higher porosity (Mascariñas $\boldsymbol{e t}$ al. 2019). The synthesized chitosan also showed an amorphous structure denoting being non-crystalline solid. This also means that the chitosan material lacks the long-range order which is also a characteristic of a crystal. Being amorphous is common to all polymers derived from raw materials like crustaceans. Also, being amorphous of the material can also pertain to a certain internal structure made of some interconnected structural blocks. This characteristic makes chitosan have higher bio-availability in the biotechnology and pharmaceutical industry than other crystalline counterparts because of its promising solubility.

FT-IR was utilized to further characterize the produced chitosan. It has established significant functional groups like amino $\left(1645.25 \mathrm{~cm}^{-1}\right)$ and hydroxyl $\left(3469.63 \mathrm{~cm}^{-1}\right)$.) The absorptions of amino and hydroxyl groups are the known primary FT-IR profiles of chitosan (Agarwal $\boldsymbol{e}$ t al., 2018). Also, the FT-IR profile of the present study was parallel to the works of Agarwal et al. (2018), Kanold et al. (2015), and Yasmeen et al. (2016) wherein chitosan was also successfully derived from various materials.

On the other hand, the yield of synthesized biomaterial plays a vital role in accessing the maximum amount can be produced from the raw material. This also measures and projects the sustainability of the source of the material. Other synthesized biomaterials in several related works appeared to be effective and efficient but then due to limited yield, it cannot be maximized into larger applications. In the current study, chitosan from blue-eyed sea urchin appeared to have a promising yield after the synthesis. The chitosan derived from the Philippine blue-eyed sea urchin has a $44.11 \%$ yield based on the previously obtained chitin. This result is closer to other studies with chitin as a reference in yield computation like the $46 \%$ yield of chitosan from shrimp shell waste (Pratiwi et al., 2014). In the study of Agarwal et al. (2018), 37-50\% of chitosan was obtained from the chitin of crustaceans. The yielded result of the present study is quite higher than that of Nessa et al. (2010) where they reported chitosan yield of $16.4-19.6 \%$. The difference in percent yield was seen due to the difference in the preparation method of chitosan as well as of chitin (Agarwal $\boldsymbol{e}$ al., 2018). On the other hand, Ahing and Wid (2016) produced 3.10-5.2g with an average of $4.09 \%$ of chitosan from shrimp shell wastes. This is computed based from the initial actual weights of the shell wastes. Previous study by Nouri et al. (2015) where they also considered the initial weights of their shell wastes showed the percentage yield of extracted chitosan ranged from 5.6-13.5\% by using a chemical method wherein the result of the present study (7.5\%) fell within the given range.

Chitosan possesses important properties like a certain cationic at certain conditions and its solubility is closely associated with its molecular weight and degree of acetylation. The process of deacetylation purifies the chitin material to be the chitosan without the acetyl groups and strengthening the hydroxyl and amino groups. The higher the deacetylation the better the chitosan is produced which also denotes lower acetylation degree. In this work, the obtained chitosan from the test wastes of blue-eyed sea urchin has 35.65\% DA. According to De Queiroz Antonino et al. (2017), the degree of acetylation of chitosan generally lies between $40 \%$ and $13 \%$. Similarly, Chatelet $\boldsymbol{e t}$ al. (2001) claim that chitosan DA is considered below $50 \%$.

On the other hand, chitosan material is commonly insoluble in most common organic solvents and water. However, it can be easily dissolved in acidic aqueous solutions $<\mathrm{pH} 6.3$. The solubility of the chitosan is very important during its application like fruit coatings. Impurities and insoluble particles of the chitosan powder could compromise its effectivity and mode of action. The solubility of chitosan is mainly associated with the degree of acetylation (Lago et al.,2011). An increase in solubility is observed with the decrease in the degree of acetylation that is evident in the present study which demonstrated $70 \%$ solubility obtained, where higher solubility means better chitosan is produced (Ahing and Wid, 2016). Chitosan showed higher solubility due to its lower acetylation values (Agarwal et al., 2018).

Meanwhile, the $\mathrm{pH}$ level decreases the absorption capacity of the urchin powder while high levels increase its adsorption capacity (Filipkowska $\boldsymbol{e t}$ al., 2010). Neutral $\mathrm{pH}$ levels are required before the deproteinization, demineralization, and deacetylation processes to balance the absorption and adsorption capacities of the urchin powder when macerated in different chemicals. Higher $\mathrm{pH}$ level in the solution of the chitosan coating could affect and interfere in the stability of the pigments of the banana samples, so $\mathrm{pH}$ that is not too strong (low acidic) is ideal in observing the effects of the coating to the bananas. In the present study, $6.5 \mathrm{pH}$ was obtained while Agarwal et al. (2018) obtained a pH of 6.7 in their chitosan which was deacetylated using $60 \% \mathrm{NaOH}$.

When it comes to the effects of the blue-eyed sea urchin chitosan to the bananas, there is a significant difference in the average weight loss percentage of each set of banana samples. The uncoated samples (control) demonstrated higher weight loss compared to the chitosan-coated samples. This means that ripening was more likely to take place faster in the bananas without chitosan. The same result was found in the work of Suseno et al. (2014), wherein weight loss of the control was higher than the chitosan-coated sample during the whole experimentation. Weight loss was slow down due to the capacity of the chitosan to serve as a coating film that could reduce water loss (Dang et al., 2010).

Meanwhile, there is also significant difference in the average peel color ratings of the banana samples in both set-ups, wherein chitosan-coated bananas had an average rating of 4 which corresponded to green color but with yellow portions, while the control had an average rating of 7 which denoted a yellow color with existing brown spots after the seven-day observation. It was also observed that the bananas without chitosan had already demonstrated yellow color as early as the $4^{\text {th }}$ day compared to the chitosan-coated which showed evident peel color change in the $5^{\text {th }}$ day. According to Pratiwi et al. (2015), the chitosan-coated fruits delayed fruit maturation which could result in slower color changes. The chitosan material, when used as fruit coating, can slow down the rate of respiration and reduce ethylene production leading to delayed fruit ripening (Kittur et al.,2001; Ali et al., 2011).

There is also a significant difference in the average ratings for the firmness of the two groups of banana samples. The control (uncoated) experienced a significant decrease in firmness, unlike the chitosan-coated bananas which maintained its firmness until $4^{\text {th }}$ day of observation. The decrease in firmness was mainly due to the softening of the banana fruit that was incorporated with the breakdown of pectin substances and movement of water from the rind of the banana pulp during ripening (Liew et al.,2012).

Lastly, there is also a significant difference in the disease incidence of the bananas with and without chitosan coatings. There seemed to have less disease occurrence in the bananas coated with chitosan compared to those without coatings. The bananas without chitosan observed to have more sooty molds and 
freckles. These are diseases mainly caused by some fungus and mealy bugs. Meanwhile, chitosan fruit coatings have proven to reduce disease incidence during the ripening process (Meng $\boldsymbol{e t}$ al., 2010; Hossain and Iqbal, 2016). Additionally, in the study of Bell et al. (1998) similar claim of chitosan's reducing disease incidence was observed.

Chitosan as fruit coating has two modes of action. Firstly, chitosan acts as a physical barrier to transpired water (Gennadios and Weller, 1990), so that chitosan-coated fruits usually have a lower weight loss and greener color than uncoated samples. Secondly, chitosan develops a modified atmosphere inside the coating by restricting oxygen consumption so that respiration and ethylene production be decreased prolonging the firmness of the chitosan-coated samples (Esti Widodo et al., 2015).

\section{CONCLUSION}

We successfully synthesized chitosan from Philippine blue-eyed sea urchin and confirmed its amorphous and non-homogenous structure as well as its hydroxyl and amino functional groups. The chitosan had potential in delaying the ripening of banana. Further studies must be conducted to test the full capacity of the synthesized biopolymer in increasing the shelf life of the fruit.

Acknowledgments: The researchers would like to express their sincerest gratitude to the Municipal Agriculture Center of Bansud, Oriental Mindoro in providing great supervision during the evaluation of the banana samples and to the De La Salle University-Physics and Chemistry Department Laboratories for the assistance in the characterization of the derived chitosan material.

\section{REFERENCES}

Abd-Alla, M.A, \& Haggag, W.M. (2010). New safe methods for controlling anthracnose disease of mango (Mangifera indica L.) fruits caused by Colletotrichum gloeosporioides (Penz.). Journal of American Science, 8(8), 361367. http://www.dx.doi.org/10.7537/marsjas060810.46

Agarwal, M., Agarwal, M. K., Shrivastav, N., Pandey, S., \& Gaur, P. (2018). A simple and effective method for preparation of chitosan from chitin. International Journal of Life-Sciences Scientific Research, 4(2), 1721-1728. https://doi.org/10.21276/ijlssr.2018.4.2.18

Ahing, F. A., \& Wid, N. (2016). Extraction and characterization of chitosan from shrimp shell waste in Sabah. Transactions on Science and Technology, 3(1-2), 227-237.

Ali, A., Muhammad, M. T. M., Sijam, K., \& Siddiqui, Y. (2011). Effect of chitosan coatings on the physicochemical characteristics of Eksotika II papaya (Carica papaya L.) fruit during cold storage. Food Chemistry, 124(2), 620-626. https://doi.org/10.1016/j.foodchem.2010.06.085

Bell, A. A., Hubbard, J. C., Liu, L., Davis, R. M., \& Subbarao, K. V. (1998). Effects of chitin and chitosan on the incidence and severity of Fusarium yellows of celery. Plant Disease, 82(3), 322-328. https://doi.org/10.1094/PDIS.1998.82.3.322

Brugnerotto, J., Lizardi, J., Goycoolea, F. M., Argüelles-Monal, W., Desbrieres, J., \& Rinaudo, M. (2001). An infrared investigation in relation with chitin and chitosan characterization. Polymer, 42(8), 3569-3580. https://doi.org/10.1016/S0032-3861(00)00713-8

Bugaud, C., Ocrisse, G., Salmon, F., \& Rinaldo, D. (2014). Bruise susceptibility of banana peel in relation to genotype and post-climacteric storage conditions. Postharvest Biology and Technology, 87, 113-119. https://doi.org/10.1016/j.postharvbio.2013.08.009

Chatelet, C., Damour, O., \& Domard, A. (2001). Influence of the degree of acetylation on some biological properties of chitosan films. Biomaterials, 22(3), 261-268. https://doi.org/10.1016/S0142-9612(00)00183-6

Dang, Q. F., Yan, J. Q., Li, Y., Cheng, X. J., Liu, C. S., \& Chen, X. G. (2010). Chitosan acetate as an active coating material and its effects on the storing of Prunus avium L. Journal of Food Science, 75(2), 125-131. https://doi.org/10.1111/j.1750-3841.2009.01483.x

de Queiroz Antonino, R., Lia Fook, B., de Oliveira Lima, V., de Farias Rached, R., Lima, E., da Silva Lima, R., ... Lia Fook, M. (2017). Preparation and characterization of chitosan obtained from shells of shrimp (Litopenaeus vannamei Boone). Marine Drugs, 15(5), https://doi.org/10.3390/md15050141

DTI (Department of Trade and Industry) - Philippines. (2004). Philippine National Standard for Fresh Fruit 'Saba' and 'Cardaba' bananas. PNS/BAFPS:2004.

Domszy, J. G., \& Roberts, G. A. (1985). Evaluation of infrared spectroscopic techniques for analyzing chitosan. Die Makromolekulare Chemie, 186(8), 16711677. https://doi.org/10.1002/macp.1985.02186081

El-Hefian, E. A., Nasef, M. M., \& Yahaya, A. H. (2011). Preparation and characterization of chitosan/poly (vinyl alcohol) blended films: mechanical, thermal and surface investigations. Journal of Chemistry, 8(1), 91-96. https://doi.org/10.1155/2011/969062

Esti Widodo, S., Zulferiyenni, Ginting, Y. C., Fazri, F. H., \& Saputra, D. (2015) Effects of 1-methylcyclopropene and chitosan on the fruit shelf-life and qualities of two different ripening stages of 'Cavendish' banana. Journal of Food and Nutrition Sciences,
https://doi.org/10.11648/j.jfns.s.2015030102.20

$3(1-2)$,

$54-59$.

$\underline{\text { https://doi.org/10.11648/j.jfns.s.2015030102.20 }}$ adsorbent concentration on the effectiveness of adsorption onto chitin and chitosan. Progress on Chemistry and Application of Chitin and its Derivatives, 15, 79-86.

Garcia, L.C. (2011). A comparative study on the antifungal effects of tamarind (Tamarindus indica) and garlic (Allium sativum) extracts on banana anthracnose. Journal of Natural Studies, 10(2), 96-107.

Gennadios, A., \& Weller, C. L. (1990). Edible films and coatings from wheat and corn proteins. Food Technology, 44(10), 63-69.

Giovannoni, J., Nguyen, C., Ampofo, B., Zhong, S., \& Fei, Z. (2017). The epigenome and transcriptional dynamics of fruit ripening. Annual Review of Plant Biology, 68, 61-84. https://doi.org/10.1146/annurev-arplant-042916$\underline{040906}$

Gomes, J. F. S., Vieira, R. R., \& Leta, F. R. (2013). Colorimetric indicator for classification of bananas during ripening. Scientia Horticulturae, 150, 201-205. https://doi.org/10.1016/j.scienta.2012.11.014

Hossain, M. S., \& Iqbal, A. (2016). Effect of shrimp chitosan coating on postharvest quality of banana (Musa sapientum L.) fruits. International Food Research Journal, 23(1), 277-283.

Hou, Y., Shavandi, A., Carne, A., Bekhit, A. A., Ng, T. B., Cheung, R. C. F., \& Bekhit, A. E. D. A. (2016). Marine shells: potential opportunities for extraction of functional and health-promoting materials. Critical Reviews in Environmental Science and Technology, 46(11-12), 1047-1116. https://doi.org/10.1080/10643389.2016.1202669

Hussain, M. R., Iman, M., \& Maji, T. K. (2013). Determination of degree of deacetylation of chitosan and their effect on the release behavior of essential oil from chitosan and chitosan-gelatin complex microcapsules. International Journal of Advanced Engineering Applications, 6, 4-12.

Kanold, J. M., Guichard, N., Immel, F., Plasseraud, L., Corneillat, M., Alcaraz, G., ... \& Marin, F. (2015). Spine and test skeletal matrices of the Mediterranean sea urchin Arbacia lixula - a comparative characterization of their sugar signature. The FEBS Journal, 282(10), 1891-1905. https://doi.org/10.1111/febs.13242

Kittur, F. S., Saroja, N., \& Tharanathan, R. (2001). Polysaccharide-based composite coating formulations for shelf-life extension of fresh banana and mango. European Food Research and Technology, 213(4-5), 306-311. https://doi.org/10.1007/s002170100363

Lago, M. A., Rodriguez Bernaldo de Quiros, A., Sendón, R., Sanches-Silva, A., Costa, H. S., Sánchez-Machado, D. I., ... \& Paseiro Losada, P. (2011). Compilation of analytical methods to characterize and determine chitosan, and main applications of the polymer in food active packaging. CyTA-Journal of Food, 9(4), 319-328. https://doi.org/10.1080/19476337.2011.603844

Liew, C. Y., \& Lau, C. Y. (2012). Determination of quality parameters in Cavendish banana during ripening by NIR spectroscopy. International Food Research Journal, 19(2),751-758.

Mahapatro, A., Singh, D.K. (2011). Biodegradable nanoparticles are excellent vehicle for site directed in-vivo delivery of drugs and vaccines. J Nanobiotechnol 9, 55. https://doi.org/10.1186/1477-3155-9-55

Majekodunmi, S. O., Olorunsola, E. O., Ofiwe, U. C., Udobre, A. S., \& Akpan, E. (2017). Material properties of chitosan from shells of Egeria radiata: drug delivery considerations. Journal of Coastal Life Medicine, 5(7), 321-324. https://doi.org/10.12980/jclm.5.2017J7-2

Mascariñas, L. R. A., Ureta, R. M., Mejico, S. M., \& Servando, C. D. (2019). Elaboration and characterization of thermal insulating material based on the synergy of natural coconut husk and disposable diaper pads fibers. International Journal of Engineering and Technologies, 17, 21-32. https://doi.org/10.18052/www.scipress.com/IJET.17.21

Meng, X., Yang, L., Kennedy, J. F., \& Tian, S. (2010). Effects of chitosan and oligochitosan on growth of two fungal pathogens and physiological properties in pear fruit. Carbohydrate Polymers, 81(1), 70-75. https://doi.org/10.1016/j.carbpol.2010.01.057

Muthiga, N. A., \& McClanahan, T. R. (2007). Ecology of Diadema Developments in Aquaculture and Fisheries Science, 37, 205-225. https://doi.org/10.1016/S0167-9309(07)80075-5

Nessa, F., Masum, S., Asaduzzaman, M., Roy, S., Hossain, M., \& Jahan, M. (2010). A process for the preparation of chitin and chitosan from prawn shell waste. Bangladesh Journal of Scientific and Industrial Research, 45(4), 323-330. https://doi.org/10.3329/bjsir.v45i4.7330

Nouri, M., Khodaiyan, F., Razavi, S. H., \& Mousavi, M. (2016). Improvement of chitosan production from persian gulf shrimp waste by response surface $\begin{array}{llll}\text { methodology. Food } & \text { Hydrocolloids, } & 59, & 50-58 .\end{array}$ https://doi.org/10.21833/ijaas.2016.10.006

Park, S. I., Daeschel, M. A., \& Zhao, Y. (2004). Functional properties of antimicrobial lysozyme-chitosan composite films. Journal of Food Science, 69(8), 215-221. https://doi.org/10.1111/j.1365-2621.2004.tb09890.x

Pratiwi, A., Dwivany, F. M., Larasati, D., Islamia, H. C., \& Martien, R. (2015). Effect of chitosan coating and bamboo FSC (fruit storage chamber) to expand 
banana shelf life. The 5th International Conference on Mathematics and Natural Sciences, 1677(100005), 1-4 https://doi.org/10.1063/1.4930763

Rafeeq, M. P. E., Junise, V., Saraswathi, R., Krishnan, P. N., \& Dilip, C. (2010). Development and characterization of chitosan nanoparticles loaded with isoniazid for the treatment of tuberculosis. Research Journal of Pharmaceutical, Biological and Chemical Sciences, 1(4), 383-390.

Sivakumar, D., Hewarathgamagae, N. K., Wilson Wijeratnam, R. S., \& Wijesundera, R. L. C. (2002). Effect of ammonium carbonate and sodium bicarbonate on anthracnose of papaya. Phytoparasitica, 30(5), 486-492. https://doi.org/10.1007/bf02979753

Suseno, N., Savitri, E., Sapei, L., \& Padmawijaya, K. S. (2014). Improving shelflife of cavendish banana using chitosan edible coating. Procedia Chemistry, 9, 113-120. https://doi.org/10.1016/j.proche.2014.05.014

Wu, Y., Weller, C. L., Hamouz, F., Cuppett, S. L., \& Schnepf, M. (2002).

Development and application of multicomponent edible coatings and films: a review. Advances in Food and Nutrition Research, 44, 347-394. https://doi.org/10.1016/s1043-4526(02)44007-7

Yasmeen, S., Kabiraz, M., Saha, B., Qadir, M., Gafur, M., \& Masum, S. (2016).

Chromium (VI) ions removal from tannery effluent using chitosanmicrocrystalline cellulose composite as adsorbent. International Research Journal of Pure and Applied Chemistry, 10(4), 1-14. https://doi.org/10.9734/irjpac/2016/23315 